\title{
A survey study on distance anatomy education: challenges unique to anatomy
}

\author{
Abdullah Ortadeveci $^{1}$ (D) $\cdot$ Merve Nur Ermez ${ }^{1} \cdot \operatorname{Semih} \mathrm{Oz}^{2} \cdot$ Hilmi Ozden $^{1}$
}

Received: 2 March 2021 / Accepted: 17 May 2021 / Published online: 24 May 2021

(c) The Author(s), under exclusive licence to Springer-Verlag France SAS, part of Springer Nature 2021

\begin{abstract}
Purpose Traditional anatomy education (TAE) is based on teaching by seeing and touching cadavers/plastic materials that enable three-dimensional thinking, but there was no opportunity like this in distance anatomy education (DAE). Due to the COVID-19 pandemic in 2020, many trainings planned face-to-face were carried out remotely. In this study, our aim is to evaluate students' views on the efficiency of DAE, and to increase the efficiency of DAE in the future.

Methods The questionnaire used in the study was applied to the first grade students in the Faculty of Medicine, at the Eskisehir Osmangazi University, in 2019-2020. 239 students completed the survey. The questionnaire consisted of the demographic information, that was obtained with voluntary consent, and sections containing suggestions on DAE, and its comparison with distance education of other basic medical science courses. The survey was prepared as a Likert scale (with $1=$ totally disagree to $5=$ totally agree), on Google forms and sent to the students online.

Results $82.4 \%$ of the students marked "totally disagree" or "disagree" for the statement of "DAE is more efficient than TAE". The total percentage of students who marked "totally disagree" or "disagree" for the statement of "I was satisfied with the theoretical education in DAE" was $58.6 \%$, but when it came to practical education the percentage raised to $79.9 \%$. Conclusions According to the results the efficiency of DAE, especially in terms of practice lessons, was found to be lower than TAE. To make DAE a powerful alternative to TAE, future studies should aim to develop a new syllabus for DAE.
\end{abstract}

Keywords Anatomy education $\cdot$ COVID-19 $\cdot$ Distance education $\cdot$ Students $\cdot$ Medical education

\section{Introduction}

The COVID-19 outbreak that started in December 2019 deeply affected many sectors, including the economy and education [22]. Social distancing which is one of the most important elements in protection from the infection, has disrupted face-to-face (F2F) education in many countries and all educations have continued remotely [1,23]. Distance medical education has revealed many problems that have not been recognized before. Studies have showed that anatomy

Previous presentation: Presented in part at the TEPARG Online Meeting 2021.

Abdullah Ortadeveci

abdullahortadeveci@gmail.com; aortadeveci@ogu.edu.tr

1 Department of Anatomy, Faculty of Medicine, Eskisehir Osmangazi University, Eskisehir, Turkey

2 Health Services Vocational School, Eskisehir Osmangazi University, Eskisehir, Turkey is one of the courses most negatively affected by distance medical education in the preclinical part of medical education [24].

Anatomy is recognized as one of the most crucial components of medical education $[8,17]$. Anatomy etymologically means "cutting up", and traditional anatomy education (TAE) is based on dissection [16]. Both the increase in technological alternatives and the insufficient number of cadaver donors has led to a decrease in cadaver dissection [11]. On the other hand, studies have revealed the negative effect of cadaveric contact on students such as fear, anxiety [2]. Although all these factors accelerated the need for an alternative anatomy education model to cadaver-based education, there was no consensus on the proposed methods.

TAE in Faculty of Medicine, Eskisehir Osmangazi University (ESOGU) is carried out with cadavers, real-like plastic models, three-dimensional (3D) applications, and visuals. While learning anatomy, students benefit from many different learning styles such as seeing, touching, 3D perception, association, and discussing in small groups. However, the 
use of these learning styles has significantly decreased during distance anatomy education (DAE). Also, some learning activities such as discussions, practice by doing, and teaching others, which students can only perform in a physical classroom, have become insufficient or not used at all. Although there have been some studies dealing with DAE in the literature, very few of them depend on feedback from students.

In this study, we aimed to evaluate efficiency of DAE, and to compare DAE and TAE from the students' view. The study also reports students' opinions on comparing distance education courses of anatomy and of other basic medical sciences.

\section{Materials and methods}

The questionnaire used in the study was sent to 301 (population) students in the first grade at the Faculty of Medicine, ESOGU, which is an accredited faculty. 239 (sample) students completed the questionnaire. Our questionnaire was approved by the ESOGU Non-invasive Procedures Ethics Committee.

The questionnaire consists of three parts. Before beginning, there were statements explaining the questionnaire, its aims of study, and detailing the voluntary aspect of the participation. In the first section, there were some demographic questions that collect data such as age, gender, family income, and location. The second part consisted of the proposals obtained from studies in the literature and prepared with a Likert scale (with $1=$ totally disagree to $5=$ totally agree) $[5,20,27]$. The survey also included statements measuring the efficiency of DAE and comparing it with the distance education of other basic sciences' courses. In the last part, there was an open-ended non-mandatory question about students' views for bettering DAE.

The questionnaire was prepared on Google Forms was sent to the students via the internet and the results were obtained. Cronbach's alpha value was calculated for the Likert scale questions. Cronbach's Alpha overall reliability coefficient for the questionnaire was calculated as 0.924 . The results were analyzed and interpreted as frequency analysis.

The participants of the study had started their anatomy education in the fall semester. These students received F2F training until the middle of the spring semester, and after the COVID-19 measures were taken, they completed most of the semester remotely. In this way, the participated students in our study had gained personal experience to compare TAE and DAE. In our faculty, DAE has been carried out by making vocalized presentations, and videos showing anatomic structures from laboratory materials and cadaveric specimens available to students. The only topics that the participants were taught F2F was bones, joints and upper extremity muscles. On the other hand, DAE topics included muscles of lower extremity and trunk, peripheral vessels and nerves.

\section{Results}

$131(54.8 \%)$ of the participants were female, 108 (45.2\%) were male. While $84.1 \%$ of the participants were between the ages of $17-21,82.2 \%$ of them had not completed their second year of medical school. Only $3.8 \%$ of the students participating in our study were from the countryside.

$59.4 \%$ of the students marked "totally disagree" for the statement "DAE makes the student more active in terms of teaching practices". This ratio was determined as $27.2 \%$ in "DAE enables students to learn at their own pace". $26.8 \%$ of the participants marked the negative options ("totally disagree" or "disagree") in the statement that they could organize the working time in remote education themselves. Other proposals about regarding this part, and the results are presented in Table 1.

Most of the students were negative towards the statement "DAE is suitable for me" (47.3\% marked "totally disagree"). More than $80 \%$ of the participants negatively replied to the proposal "DAE is more effective than TAE" (66.1\% marked "totally disagree", $16.3 \%$ marked "disagree"). While $58.6 \%$ of the students marked "totally disagree" or "disagree" for the statement, "I am satisfied with theoretical education in DAE", this rate was calculated as $89.9 \%$ when the same proposal was given for practice. All the expressions measuring the learning and satisfaction of the students and the results obtained are given in Table 2.

More than half of the students agreed that they had more difficulty in anatomy in distance education compared to other basic science courses (37.7\% marked "totally agree" and 31.4\% marked "agree"). Most of the students agreed with the statement that it takes more time to learn anatomy practice lessons than other basic medical science courses in F2F education (31\% marked "totally agree" and 39.7\% marked "agree"). A significant majority of the participants were of the common opinion that the practice lessons in TAE offered advantages in terms of 3D thinking and visual perception (59\% marked "totally agree" and $27.6 \%$ marked "agree") (Table 3).

For the future, the students expressed their supportive opinions to the suggestions about rearranging the course contents of DAE, and using more visual materials (51.5\% and $61.1 \%$ marked "totally agree", respectively) (Table 4).

In the last part, students' suggestions for a better model of DAE were elicited with an open-ended question. In this question answered by 66 students, many students stated that practice lessons cannot be understood without F2F 
Table 1 Results of all expressions on "personal suitability, student autonomy, and technical issues"

\begin{tabular}{|c|c|c|c|c|c|}
\hline Expressions $(n=239)$ & Totally disagree & Disagree & Neutral & Agree & Totally agree \\
\hline DAE saves time & $97(40.6 \%)$ & $51(21.3 \%)$ & $53(22.2 \%)$ & $19(7.9 \%)$ & $19(7.9 \%)$ \\
\hline DAE provides locational flexibility & $65(27.2 \%)$ & $50(20.9 \%)$ & $65(27.2 \%)$ & $35(14.6 \%)$ & $24(10.0 \%)$ \\
\hline DAE enables students to learn at their own pace & $65(27.2 \%)$ & $55(23.0 \%)$ & $62(25.9 \%)$ & $39(16.3 \%)$ & $18(7.5 \%)$ \\
\hline DAE makes the student more active in terms of teaching practices & $142(59.4 \%)$ & $47(19.7 \%)$ & $30(12.6 \%)$ & $15(6.3 \%)$ & $5(2.1 \%)$ \\
\hline Content of the lessons in DAE is sufficient in terms of learning & $113(47.3 \%)$ & $71(29.7 \%)$ & $31(13.0 \%)$ & $17(7.1 \%)$ & $7(2.9 \%)$ \\
\hline DAE provides a decent learning opportunity for people & $105(43.9 \%)$ & $71(29.7 \%)$ & $38(15.9 \%)$ & $18(7.5 \%)$ & $7(2.9 \%)$ \\
\hline In DAE, I decide myself what and how to learn & $51(21.3 \%)$ & $47(19.7 \%)$ & $62(25.9 \%)$ & $54(22.6 \%)$ & $25(10.5 \%)$ \\
\hline In DAE, I can organize the working time according to myself & $38(15.9 \%)$ & $26(10.9 \%)$ & $64(26.8 \%)$ & $69(28.9 \%)$ & $42(17.6 \%)$ \\
\hline In DAE, I play an active role in the learning process & $67(28.0 \%)$ & $55(23.0 \%)$ & $64(26.8 \%)$ & $37(15.5 \%)$ & $16(6.7 \%)$ \\
\hline In DAE, I have a unique learning style & $41(17.2 \%)$ & $39(16.3 \%)$ & $73(30.5 \%)$ & $60(25.1 \%)$ & $26(10.9 \%)$ \\
\hline $\begin{array}{l}\text { I was able to get technical support when I had problems accessing the } \\
\text { system }\end{array}$ & $33(13.8 \%)$ & $37(15.5 \%)$ & $104(43.5 \%)$ & $31(13.0 \%)$ & $34(14.2 \%)$ \\
\hline $\begin{array}{l}\text { I was able to get the necessary support when I had problems with the } \\
\text { lessons }\end{array}$ & $58(24.3 \%)$ & $59(24.7 \%)$ & $82(34.3 \%)$ & $24(10.0 \%)$ & $16(6.7 \%)$ \\
\hline $\begin{array}{l}\text { I was able to convey my requests and suggestions about the courses to } \\
\text { the authorities }\end{array}$ & $55(23.0 \%)$ & $76(31.8 \%)$ & $72(30.1 \%)$ & $24(10.0 \%)$ & $12(5.0 \%)$ \\
\hline When necessary, I was able to interact with the lecturers of the courses & $71(29.7 \%)$ & $74(31.0 \%)$ & $63(26.4 \%)$ & $21(8.8 \%)$ & $10(4.2 \%)$ \\
\hline
\end{tabular}

Table 2 Results of all expressions on "learning, effectiveness, and satisfaction"

\begin{tabular}{|c|c|c|c|c|c|}
\hline Expressions $(n=239)$ & Totally disagree & Disagree & Neutral & Agree & Totally agree \\
\hline DAE provides the convenience of receiving education from home & $62(25.9 \%)$ & $38(15.9 \%)$ & $65(27.2 \%)$ & $40(16.7 \%)$ & $34(14.2 \%)$ \\
\hline I think DAE is suitable for me & $113(47.3 \%)$ & $51(21.3 \%)$ & $35(14.6 \%)$ & $26(10.9 \%)$ & $14(5.9 \%)$ \\
\hline DAE is a suitable alternative for the training I need & $93(38.9 \%)$ & $70(29.3 \%)$ & $39(16.3 \%)$ & $25(10.5 \%)$ & $12(5.0 \%)$ \\
\hline DAE is suitable for me due to the intensity of my work & $107(44.8 \%)$ & $52(21.8 \%)$ & $38(15.9 \%)$ & $24(10.0 \%)$ & $18(7.5 \%)$ \\
\hline In DAE, I was satisfied with the anatomy practical training & $137(57.3 \%)$ & $54(22.6 \%)$ & $33(13.8 \%)$ & $8(3.3 \%)$ & $7(2.9 \%)$ \\
\hline In DAE, I was satisfied with the anatomy theoretical training & $66(27.6 \%)$ & $74(31.0 \%)$ & $64(26.8 \%)$ & $23(9.6 \%)$ & $12(5.0 \%)$ \\
\hline Overall, I was satisfied with the DAE & $78(32.6 \%)$ & $85(35.6 \%)$ & $47(19.7 \%)$ & $19(7.9 \%)$ & $10(4.2 \%)$ \\
\hline DAE ensures permanent learning & $144(60.3 \%)$ & $48(20.1 \%)$ & $34(14.2 \%)$ & $9(3.8 \%)$ & $4(1.7 \%)$ \\
\hline I understood the lessons in DAE & $69(28.9 \%)$ & $82(34.3 \%)$ & $60(25.1 \%)$ & $22(9.2 \%)$ & $6(2.5 \%)$ \\
\hline
\end{tabular}

Table 3 Results of all expressions on "challenges in distance education unique to anatomy" and "TAE vs DAE"

\begin{tabular}{|c|c|c|c|c|c|}
\hline Expressions $(n=239)$ & Totally disagree & Disagree & Neutral & Agree & Totally agree \\
\hline DAE is more effective than TAE & $158(66.1 \%)$ & $39(16.3 \%)$ & $25(10.5 \%)$ & $11(4.6 \%)$ & $6(2.5 \%)$ \\
\hline $\begin{array}{l}\text { In TAE, anatomy practice lessons provide the advantage of three- } \\
\text { dimensional thinking and visual perception, as they include materials } \\
\text { such as models and cadavers }\end{array}$ & $5(2.1 \%)$ & $7(2.9 \%)$ & $20(8.4 \%)$ & $66(27.6 \%)$ & $141(59.0 \%)$ \\
\hline $\begin{array}{l}\text { In TAE, it takes more time to comprehend practical lessons in anatomy } \\
\text { (model. cadaver lessons. etc.) compared to other basic science courses } \\
\text { (physiology, histology-embryology, microbiology, etc.) }\end{array}$ & $6(2.5 \%)$ & $11(4.6 \%)$ & $53(22.2 \%)$ & $95(39.7 \%)$ & $74(31.0 \%)$ \\
\hline $\begin{array}{l}\text { In distance education, basic science courses other than anatomy are } \\
\text { easier to learn than anatomy }\end{array}$ & $10(4.2 \%)$ & $14(5.9 \%)$ & $78(32.6 \%)$ & $73(30.5 \%)$ & $64(26.8 \%)$ \\
\hline $\begin{array}{l}\text { I had more difficulty in DAE compared to distance education of other } \\
\text { basic science courses }\end{array}$ & $5(2.1 \%)$ & $19(7.9 \%)$ & $50(20.9 \%)$ & $75(31.4 \%)$ & $90(37.7 \%)$ \\
\hline I think that DAE is not as effective as TAE & $10(4.2 \%)$ & $15(6.3 \%)$ & $34(14.2 \%)$ & $69(28.9 \%)$ & $111(46.4 \%)$ \\
\hline
\end{tabular}


Table 4 Results of all expressions on "What to do in DAE in the future?"

\begin{tabular}{|c|c|c|c|c|c|}
\hline Expressions $(n=239)$ & Totally disagree & Disagree & Neutral & Agree & Totally agree \\
\hline In the future, lessons in DAE should be taught more interactively & $6(2.5 \%)$ & $11(4.6 \%)$ & $74(31.0 \%)$ & $54(22.6 \%)$ & $94(39.3 \%)$ \\
\hline $\begin{array}{l}\text { In the future, lesson contents in DAE should be rearranged in } \\
\text { accordance with distance education needs }\end{array}$ & $5(2.1 \%)$ & $1(0.4 \%)$ & $37(15.5 \%)$ & $73(30.5 \%)$ & $123(51.5 \%)$ \\
\hline In the future, lesson duration in DAE should be shorter & $41(17.2 \%)$ & $36(15.1 \%)$ & $92(38.5 \%)$ & $32(13.4 \%)$ & $38(15.9 \%)$ \\
\hline In the future, lessons in DAE should include more visual material & $2(0.8 \%)$ & $1(0.4 \%)$ & $28(11.7 \%)$ & $62(25.9 \%)$ & $146(61.1 \%)$ \\
\hline
\end{tabular}

classroom, so a hybrid education model should be implemented. Many students expressed that they wanted to come back to school and missed it immensely. Besides, the answers included suggestions such as enriching the lectures with visual materials, adding additional explanatory videos, conducting the lessons synchronously, supporting the lessons with 3D programs, and lecturing on YouTube channels.

\section{Discussion}

There are serious differences between learning models offered to students in TAE and DAE. Anatomy education, especially the practical aspect, requires a physical environment. In addition to passive learning styles such as watching, listening, and reading, students also use active learning methods effectively by explaining to their friends and discussing the subject amongst themselves. It has been previously stated in the literature that active learning methods have more positive effects on learning efficiency [15]. In addition, learning anatomical structures by touching them on cadavers, models and participating in dissection sessions may contribute to the development of anatomic abilities of students.

In our study, we aimed to evaluate the pros and cons of DAE from students' view and learn the students' opinions about the changes that should be made in the future to DAE. According to the results, the students have found the efficiency of DAE to be lower than TAE. They have stated that they were not satisfied with the DAE in terms of both theoretical and practical aspects. On the other hand, the answers given revealed that DAE has relatively acceptable aspects in terms of individual suitability and student autonomy.

\section{Suitability, autonomy, and technical issues}

In a study conducted on the medical faculty and dentistry students, most of the students stated that they had difficulty in time management and they had difficulties in focusing on DAE due to the uncomfortable or excessive comfortable conditions at home [25]. In the same study, $69 \%$ of the students stated that they felt self-motivation deficiencies [25]. Parallel to this study, the students who participated in our study did not think that DAE was time-saving. Although online education offers many facilities to students, these results show poor students' satisfaction. One of the important reasons for this negative tendency may be the familiarity of students with traditional education for many years. The results of all the studies in this field, an important variable is personal and regional factors such as geography, upbringing style, and self-awareness.

Students expressed their satisfaction arising from the freedom and flexibility provided by distance education [24]. In our study, however, the students put forward negative opinions about the efficiency in DAE, but took a more moderate position against technical issues, autonomy, and suitability. Although students have many different options about participating in DAE, the reason for the difference may be the social limitations during COVID-19. When the opinions of the students on technical issues were taken, $83 \%$ stated that the lack of suitable equipment and a strong internet connection was an obstacle to learning [25]. In our study, the students did not show any significant distribution against the proposals about technical problems. The fact that a very small minority of the students in our study joined lessons from the rural area $(3.8 \%)$, and that the remaining participants had sufficient internet infrastructure in their residential areas may have contributed to the relatively positive results of our study.

\section{Learning, effectiveness, and satisfaction}

DAE is a challenging process for both educators and learners. Even if the technical infrastructure has been thoughtfully and well planned, it is still very challenging to achieve the traditional education quality in a subject that requires intensive practicals. The students participating in our study stated that they were not satisfied with the DAE, especially the practical aspect. In another study, students consistently reported that "they have lost their clinical skills, and laboratory-based training was being negatively affected" [24]. The discussions on whether distance education is more efficient synchronously or asynchronously still ongoing. A meta-analysis by $\mathrm{He}$ et al., revealed that there is no significant difference between synchronized distance medical education and traditional medical 
education [9]. Since the participants of our study did not have synchronous training experience, they were not asked to compare the difference between synchronous and asynchronous anatomy training.

A study conducted by Viswasom et al. showed that the video-supported TAE increases the efficiency of TAE [26]. Similarly, another study concluded that watching videos is a passive learning style, but it may be more efficient to include videos in an active learning style [13]. The results of our study showed that the efficiency of the practical training carried out only through videos was quite low. While the students stated in their answers to the open-ended question that using more video materials would increase efficiency. However, in our study, no investigation was made into reflections regarding the effectiveness of video-based anatomy training on exam performance. In the study conducted by Ozer et al., web-based video packages were presented to students and it was revealed that this teaching style contributed to students' learning at their own pace. In addition, although the cost of the presented system is low, it has been suggested that it is a factor that increases self-motivation because it is accessible at any time for students [19]. Students who attended the online anatomy education at Edinburgh University stated that videos are efficient and funny for anatomy education, and it is important to have the option to fast forward or rewind. Students participating in the same study reported that some complex structures could not be understood from the videos. The study predicted that these problems could be solved by adding transcription to the anatomic videos [12]. When all these points are taken into consideration, it can be concluded that video-assisted anatomy training will be more efficient than a video-based anatomy training. Adding the names of anatomical structures as subtitles in the lecture videos is an option to increase efficiency.

\section{TAE vs DAE}

The last few decades have seen many significant changes, advances and modernization of TAE. Cadaver dissection and drawings, which have been the basis of anatomy education for hundreds of years, are widely discussed even today [7]. Still medical students stated that cadavers and anatomic specimens in TAE could not be replaced in the DAE [24]. In another study evaluating the anatomy education of medical and dental students during the COVID-19 pandemic, it was revealed that $65 \%$ of the students agreed that they miss TAE [25]. Similarly, in our study, the students' feedbacks to the open-ended question revealed that they missed TAE. Many students used the phrase "please call us back to the faculty".

\section{Challenges in distance education unique to anatomy}

Discussions are ongoing about the efficiency of distance medical education. Anatomy is one of the practice-based courses in preclinical medical education. A study investigating the effects of distance education on students revealed that $90 \%$ of the students felt negatively regarding the lessons that require practical experience, such as anatomy [24]. In another study, students stated that anatomy education without dissection, models, and other facilities caused a lack of confidence and difficulty in understanding [25]. In cases where F2F education cannot be continued, the anatomists around the world is looking into powerful innovative alternatives to minimize these negative effects on students. Studies have revealed that students who apply traditional dissection in combination with virtual dissection have shown a significant improvement in learning outcomes [3]. In our study, the questions that make comparisons between anatomy and other basic science courses indicate that one of the most difficult lessons to learn through distance medical education is anatomy. Another study made evaluations on distance educations of histology and anatomy. Although histology is a visual field like anatomy, the results indicate that $3 \mathrm{D}$ visualization is needed to create a good base of anatomical knowledge [18]. All these studies have suggested that the efficiency of DAE that is carried out without F2F practice will not be efficient enough. The probable reason for this is the nature of anatomy, because anatomy is based on visual learning and 3D thinking. DAE still has a long way to go. The fact that there is currently no DAE model as efficient as TAE does not mean that will be the case forever. The future of DAE needs to develop a more efficient syllabus that can be used at least during natural disasters or emergencies.

\section{What to do in DAE in the future?}

Technological possibilities that develop day by day have an effect on the education of anatomy. The new generation of students need an anatomical education equipped with new technologies. It is stated in the literature that quizzes, competitions, social communication tools, and discussions that provide a warming up, at the beginning of the lesson will be useful to increase the efficiency of online trainings $[4,14]$. Some studies have stated that the interaction can be increased by conducting lessons via YouTube in online education. They also stated that in-class competition and excitement can positively contribute to applications such as Kahoot [21]. According to the results of our study, the students showed a serious consensus towards the reorganization of the course contents of the future DAE on being more interactive and having visually enriched lessons. Lecturers 
are also trying to increase the efficiency of distance education. These attempts require re-adapting to the changing education system and revising the course contents. A study revealed that a mix of $\mathrm{F} 2 \mathrm{~F}$ and online anatomy training puts an extra burden on educators [6]. However, with these innovations, new necessities will arise, and a well-designed DAE will incur new costs for the institution.

The use of anatomy education models, coupled with technology is increasing $[19,26]$. Iwanaga et al. made it possible for participants from different parts of the world to feel like they are together in the same classroom, with the help of 3D Virtual Reality (VR) workshop. It has been stated that 3D VR systems, in which the participants can also intervene, can increase the participation of students in the course and facilitate their understanding of surgical procedures and anatomical structures [10]. All these developments reveal that in the near future, systems integrated with technology will have a strong place in the education of anatomy.

\section{Conclusion}

The results we obtained in our study show that the efficiency of DAE is low. It is noteworthy that our study was conducted on only our faculty's students. The obtained results may have been affected by many reasons such as teaching methods, technical competencies, didactic differences, different anatomy topics, etc. Controlled national and international studies in which different education methods are presented to groups of similar students with the same instructors and to include the same topics can minimize the misleading factors.

In terms of the efficiency of distance education in the future, students should focus on self-discipline and selfstudy. By organizing online laboratory classes with the participation of lecturers as a spectator, an online classroom can be organized for students to learn by discussing and teaching each other. Course content should be strengthened with quizzes and online participatory activities. Since the efficiency of practice-based lessons such as anatomy in distance education is lower than those with the need for less practice, the lesson schedules should be organized taking this factor into consideration. Also, organizing the theoretical parts of the courses online and the practical parts of them F2F (hybrid anatomy education) can be a powerful alternative, that may meet many of the features that students need to learn. There is still a crucial requirement to improve both the theoretical and practical aspects of distance medical education. In this context, all alternatives should be evaluated and the effects of a hybrid education style should be investigated.
Acknowledgements All the authors declare that they have participated in the design, execution, and analysis of the paper, and that they have approved the final version. This study does not have any funding.

Author contribution A. Ortadeveci; Protocol development. Data collection and analysis. Manuscript writing. MN Ermez; data collection and analysis. Manuscript writing. S Oz; data management. Manuscript editing. H Ozden; protocol development. Manuscript editing.

Funding The authors received no funding to conduct this study.

Availability of data and material Tables are available. No tissue samples exist.

\section{Declarations}

Conflict of interest The authors have no conflicts of interest to disclose.

Ethics approval The study was approved by the "ESOGU Non-invasive Clinical Researches Ethics Committee" on 14.07.2020 (Decree no: 18).

Consent to participate All authors approve of their participation in the study.

Consent for publication All authors approve the publication of the study.

\section{References}

1. Ahmed H, Allaf M, Elghazaly H (2020) COVID-19 and medical education. Lancet Infect Dis 20:777-778. https://doi.org/10.1016/ S1473-3099(20)30226-7

2. Bahşi İ, Topal Z, Çetkin M, Orhan M, Kervancıŏ̆lu P, Odabaşığlu ME, Cihan ÖF (2020) Evaluation of attitudes and opinions of medical faculty students against the use of cadaver in anatomy education and investigation of the factors affecting their emotional responses related thereto. Surg Radiol Anat 43:1-7. https://doi.org/10.1007/s00276-020-02567-8

3. Boscolo-Berto R, Tortorella C, Porzionato A, Stecco C, Picardi EEE, Macchi V, De Caro R (2021) The additional role of virtual to traditional dissection in teaching anatomy: a randomised controlled trial. Surg Radiol Anat 43:469-479. https://doi.org/10. 1007/s00276-020-02551-2

4. Chen NS, KoKinshukLin HCT (2005) A model for synchronous learning using the Internet. Innov Educ Teach Int 42:181-194. https://doi.org/10.1080/14703290500062599

5. Eygu H, Karaman S (2013) A study on the satisfaction perceptions of the distance education students. KUJSS 3:36-59

6. Green RA, Whitburn LY (2016) Impact of introduction of blended learning in gross anatomy on student outcomes. Anat Sci Educ 9:422-430. https://doi.org/10.1002/ase.1602

7. Grignon B, Duparc F (2021) New insights in anatomical education. Surg Radiol Anat 43:1. https://doi.org/10.1007/ s00276-021-02737-2

8. Haque AE, Haque M, Than M, Khassan L, Ishak A, Azmi A, Rezal M (2017) Perception on the use of plastinated specimen in anatomy learning among preclinical medical students of UNIKL RCMP, Malaysia. J Glob Pharm Technol 9:25-33

9. He L, Yang N, Xu L, Ping F, Li W, Sun Q, Li Y, Zhu H, Zhang H (2020) Synchronous distance education vs traditional education 
for health science students: a systematic review and meta-analysis. Med Educ 55:293-308. https://doi.org/10.1111/medu.14364

10. Iwanaga J, Kamura Y, Nishimura Y, Terada S, Kishimoto N, Tanaka T, Tubbs RS (2021) A new option for education during surgical procedures and related clinical anatomy in a virtual reality workspace. Clin Anat 34:496-503. https://doi.org/10.1002/ca. 23724

11. Iwanaga J, Loukas M, Dumont AS, Tubbs RS (2020) A review of anatomy education during and after the COVID-19 pandemic: revisiting traditional and modern methods to achieve future innovation. Clin Anat 34:108-114. https://doi.org/10.1002/ca.23655

12. Kelsey AH, McCulloch V, Gillingwater TH, Findlater GS, Paxton JZ (2020) Anatomical sciences at the University of Edinburgh: initial experiences of teaching anatomy online. Transl Res Anat 19:100065. https://doi.org/10.1016/j.tria.2020.100065

13. Langfield T, Colthorpe K, Ainscough L (2018) Online instructional anatomy videos: student usage, self-efficacy, and performance in upper limb regional anatomy assessment. Anat Sci Educ 11:461-470. https://doi.org/10.1002/ase.1756

14. Martin F, Bolliger DU (2018) Engagement matters: student perceptions on the importance of engagement strategies in the online learning environment. OLJ 22:205-222. https://doi.org/10.24059/ olj.v22i1.1092

15. Masters K (2013) Edgar Dale's pyramid of learning in medical education: a literature review. Med Teach 35:1584-1593. https:// doi.org/10.3109/0142159X.2013.800636

16. McLachlan JC, Bligh J, Bradley P, Searle J (2004) Teaching anatomy without cadavers. Med Educ 38:418-424. https://doi.org/10. 1046/j.1365-2923.2004.01795.x

17. McLachlan JC, Patten D (2006) Anatomy teaching: ghosts of the past, present and future. Med Educ 40:243-253. https://doi.org/ 10.1111/j.1365-2929.2006.02401.x

18. Mustafa AG, Taha NR, Alshboul OA, Alsalem M, Malki ME (2020) Using Youtube to learn anatomy: perspectives of Jordanian medical students. BioMed Res Int 2020:8. https://doi.org/10.1155/ 2020/6861416

19. Ozer MA, Govsa F, Bati AH (2017) Web-based teaching video packages on anatomical education. Surg Radiol Anat 39:12531261. https://doi.org/10.1007/s00276-017-1889-9

20. Ozkok A, Walker SL (2009) Assessment of psychosocial learning environment in the distance education. In: Proceedings of 9th international educational technology conference, pp 425-428
21. Pather N, Blyth P, Chapman JA, Dayal MR, Flack NA, Fogg QA, Green RA, Hulme AK, Johnson IP, Meyer AJ (2020) Forced disruption of anatomy education in Australia and New Zealand: an acute response to the Covid-19 pandemic. Anat Sci Educ 13:284300. https://doi.org/10.1002/ase.1968

22. Paules CI, Marston HD, Fauci AS (2020) Coronavirus infections-more than just the common cold. JAMA 323:707-708. https://doi.org/10.1001/jama.2020.0757

23. Prem K, Liu Y, Russell TW, Kucharski AJ, Eggo RM, Davies N, Flasche S, Clifford S, Pearson CA, Munday JD (2020) The effect of control strategies to reduce social mixing on outcomes of the COVID-19 epidemic in Wuhan, China: a modelling study. Lancet Public Health 5:261-270. https://doi.org/10.1016/S2468-2667(20) 30073-6

24. Shahrvini B, Baxter SL, Coffey CS, MacDonald BV, Lander L (2021) Pre-clinical remote undergraduate medical education during the COVID-19 pandemic: a survey study. BMC Med Educ 21:13. https://doi.org/10.1186/s12909-020-02445-2

25. Singal A, Bansal A, Chaudhary P, Singh H, Patra A (2020) Anatomy education of medical and dental students during COVID-19 pandemic: a reality check. Surg Radiol Anat 43:515-521. https:// doi.org/10.1007/s00276-020-02615-3

26. Viswasom AA, Jobby A (2017) Effectiveness of video demonstration over conventional methods in teaching osteology in anatomy. J Clin Diagn Res 11:JC09-JC11. https://doi.org/10.7860/JCDR/ 2017/24029.9429

27. Walker SL, Fraser BJ (2005) Development and validation of an instrument for assessing distance education learning environments in higher education: The Distance Education Learning Environments Survey (DELES). Learn Environ Res 8:289-308. https:// doi.org/10.1007/s10984-005-1568-3

Publisher's Note Springer Nature remains neutral with regard to jurisdictional claims in published maps and institutional affiliations. 